\title{
IS THERE REALLY A PUZZLE OVER NEGATIVE EMOTIONS AND AESTHETIC PLEASURE?
}

\section{María José Alcaraz León}

\begin{abstract}
Two seemingly contradictory aspects have marked art's appreciation - and aesthetic appreciation in general. While an experience of pleasure seems to ground judgments of aesthetic value, some artworks seem to gain our praise by the very negative - unpleasant - experience they provoke. Known as the paradox of negative emotions, aestheticians have, at least since Aristotle, tried to deal with these cases and offer different explanations of the phenomenon. In this article, María José Alcaraz León does not directly offer an alternative explanation; rather she focuses on the apparent tension between an understanding of aesthetic experience in terms of a certain kind of pleasure and the negative aspect that is necessarily involved in our appreciation of painful art. The purpose of her article is to show that cases of artistic appreciation that involve negative emotions do not need to give up on the idea that aesthetic value is ultimately grounded upon an experience of pleasure.
\end{abstract}

KEYWORDS

Negative emotions, Aesthetic pleasure, Aesthetic value, Paradox

Attention to tragedy, horror films or narratives, the sublime or, more recently, artworks that traffic with disgust, have frequently led to concern about the so called puzzle of negative emotions. ${ }^{1}$ The conundrum arises because (i) aesthetic experience is usually characterized in terms of some pleasurable experience, (ii) good tragedies, horror films, etc., seem to be better - as artworks - when the negative emotions aroused by them are also intense or fully accomplished, and (iii) the value of an artwork as an artwork is based upon the aesthetic experience it affords.

Given these three claims, what seems hard to explain is how experiencing the negative emotions usually associated with these genres can play a role in a positive aesthetic experience or aesthetic pleasure. How, in brief, can some pleasurable experience be derived from the experience of negative, allegedly painful, emotions? 
At least since Hume's essay "Of Tragedy," 2 a great amount of solutions have been offered in order to dissipate or at least diminish the force of the puzzle and to properly locate the negative experience usually associated with the appreciation of these works within a cogent characterization of aesthetic experience. ${ }^{3}$

Roughly, these accounts can be divided into two groups. On the one hand, there are those which try to explain how the negative emotional response does not preclude a more general positive experience (either because the negative is to some extent transformed into some positive experience 4 or because it essentially contributes to the presence of some positive aspect) ${ }^{5}$; and, on the other hand, there are proposals which hold we should give up the idea that aesthetic experience or aesthetic value are primarily linked to pleasure ${ }^{6}$ - thus solving the puzzle by rejecting the idea (i).

In this article, I would like to explore the possibility of keeping the full negative character of so-called negative emotions within the structure of aesthetic experience without renouncing the idea that aesthetic experience is to be mainly understood in terms of pleasure. Since I would like to keep the negative aspect as part of the aesthetic experience, I cannot afford alternative explanations of the puzzle which, so to say, transform the negative into the positive; or that provide an explanation of the puzzle which attach some cognitive or moral value to the negative emotion. As I see it, just in virtue of attaching some further non-aesthetic value to the negative response does not solve the problem. What is needed is an explanation that illuminates the puzzling cases where the negative emotion makes the experience afforded by a work aesthetically better, and not simply cognitively greater. That is, if we want to explain the puzzle without giving up any of the claims that seemingly cause it, we need an explanation which leaves room for the idea that the aesthetic rewarding experience is partly the result of experiencing those negative emotions.

The proposal I would like to defend is grounded on some conception of aesthetic reflection as the process upon which aesthetic judgment and experience are based. I think that a proper understanding of the dynamics of aesthetic reflection can make it possible for some negative aspects to play an essential role in determining an overall aesthetic experience without renouncing the idea that the mark of aesthetic value, as the value that typically aesthetic experiences affords, is an experience of pleasure. Thus, I believe that a closer look at what aesthetic experience is, and how it results from aesthetic reflection, may help us to see why this puzzle of the negative emotions and aesthetic value is 
only apparent. Although I cannot offer a full picture of aesthetic reflection here, I think that paying attention to some established features of this particular sort of reflective activity - at least since Kant's characterization of the reflective judgment - can provide some hints to dissolve the puzzle.

Nevertheless, before laying out my own proposal I will mention some of the most prominent solutions to the problem of negative emotions and aesthetic value, ${ }^{7}$ and I will briefly point to some problems, which I think make them insufficient explanations.

\section{SOME PROPOSALS TO SOLVE THE PUZZLE}

Although I cannot offer here a full revision of the different proposals which have been offered in order to explain away the paradox, I would like to point to some of the arguments and explanations that have been aiming at solving this problem. However, as I will try to show, I think that the proposals revised in this section are either insufficient, or they misallocate the source of pleasure, or they involve completely giving up on the idea of pleasure as being characteristic to aesthetic value.

As it has become a classic starting point in this debate we could begin with Hume's solution to the paradox - or at least some established, accepted reading of his solution. Hume's solution is usually referred to as the conversion solution, for he claims that the pleasure of tragedy can be understood in terms of the transformation of negative feelings into positive ones through the power of the beauty and eloquence of the poet's words. ${ }^{8}$

According to Hume, then, the negative feelings triggered by the represented events are converted into positive sentiments through the pleasure derived from the formal features of the representation.

Although this view has the virtue of acknowledging the role of the representational medium in the viewer's response, I think it fails to solve the problem for several reasons. First, no story is offered in order to explain how this transformation of feeling occurs. Why should one sentiment (the positive one which derives from the beauty of the representation) overpower the other (the negative one elicited by the painful events)? Why should one kind of feeling subdue the other? There is no reason to believe this must be so or, if it were the case that the two contrasting effects (one positive and the other negative) are triggered by a work, that one of them necessarily overcomes the other.

Moreover, this solution also seems to undermine the role that the negative affect plays in the alleged pleasure that these paradoxical works elicit. For the core of the paradox is precisely that 
the pain derived from these works is not dissolved or overcome, but remains an essential component of this very peculiar kind of pleasure that we find puzzling. In fact, Hume himself seems to be aware of this. ${ }^{9}$

Finally, a further problem with Hume's view is that it could only work for representational art forms where the eloquence and rhetorical effects could diminish and, allegedly convert, the negative feelings into positive ones. However, it would leave unexplained why we also find paradoxical the experience of negative emotions, such as sadness or melancholy, in non-representational artworks, such as music. ${ }^{10}$

A second, straightforward way to dissolve the paradox would be to hold that there are no real (negative or positive) emotions involved in our appreciation of artworks, ${ }^{\mathbf{1 1}}$ or that the emotions experienced, albeit possessing some negative qualitative aspect, are not fully experienced as negative. One recent defence of a solution to the paradox along this line is Cain Todd's proposal.12 According to both versions of the idea that emotions felt towards fictional events are not real or at least fully-fledged emotions, the reason for the attenuated character of emotions elicited by works of art is that the viewer never loses awareness of the fictional character of the events to which she responds. Thus, the canonical intentional state towards what is represented in a novel or film is not one of belief but of make-believe; and hence we do not respond with crude, real emotions, towards that content precisely because we know that the things represented in the work are not real. Rather, since we merely imagine that the things are as they are represented by the work, we feel emotional states that, while phenomenologically similar to real emotions, are experienced in an attenuated manner. This, in turn, makes it possible that our sadness towards fictional contents is not experienced as harmfully as real sadness and hence it could contribute to the overall pleasure that gives the work its value.

Although it may be true that not all of the alleged negative emotions felt towards painful art need to be strongly experienced or felt in a way that mirrors the unbearable character of some ordinary negative feelings, I think this solution partly reduces the appeal of the paradox by diminishing one of its premises' strengths; that is, by rejecting that we feel genuine painful emotions towards certain works of art. Certainly, if the emotional states we typically feel when appreciating works of art are not as vivid or real as ordinary emotions, the air of paradox easily vanishes. Remember that the paradox arose precisely because we seem to experience a great 
pleasure with works, which also cause negative feelings in us; so, if we get rid of the force of the unpleasant character of our emotional responses altogether, the air of paradox would consequently fade out.

However, I think we should at least attempt at taking the paradox seriously in its own terms without weakening any of the claims that give rise to it. That is, we should not assume that emotional responses to art are to be less intense or vivid than real emotions. In fact, if we pay attention to some behaviour that appreciators typically exhibit when responding emotionally to artworks, we have reasons to think that in many cases the emotions felt are experienced as vividly as real ones.

Moreover, I think both Walton and Todd could only be said to offer a partial solution to the problem for, as we have pointed out above against Hume's solution, the reason why they both think that the emotions felt towards art are more endurable than ordinary negative emotions is that they think they are responses to imagined fictional contents. In this sense their explanation would only work in cases where representational works of art or fictional works trigger the negative emotions. They would leave unexplained the case of experiencing negative emotions in response to musical works or in response to other non-representational arts.

A third popular explanation has appealed to some sort of positive value which is only obtained if the viewer undergoes the alleged negative experience triggered by the work. According to this view, ${ }^{13}$ the work's positive value (usually understood in terms of cognitive value) partly relies upon the work's ability to elicit some negative or unpleasant experience in the viewer. Thus, it is by virtue of undergoing the unpleasant feelings caused by the work that the viewer attains some further positive value. This line of response has been usually concocted in relation to Aristotle's view of the pleasures of tragedy and it has been extended to other kinds of typically painful genres or works. Thus, for example, although tragic events cause horror and pity in the audience, there is a further cognitive reward that is attained by purging - and maybe clarifying - those emotions. Accordingly, the reason that helps us to reconcile the negative emotions caused by the work with the value we attach to it is that the negative affective response plays a necessary role in the work's possessing some further positive cognitive value. It is by virtue of this further value achieved through painful experience that we can find value in it.

Although this explanation can work in some cases, I think it cannot provide a sufficient general explanation for the puzzle 
we are trying to clarify. First, there are cases where there is no clear cognitive benefit involved; ${ }^{14}$ or, if there is, it may be of a very general kind, or one the audience may have been acquainted with before engaging with the work. ${ }^{15}$ Besides, I think that this kind of response can only explain why the negative experience or emotions caused by the work can cause some further pleasure at the cost of instrumentalizing these negative affective responses. Contrariwise, I think we should try to explain the paradox without accepting that the only way in which something negative can contribute to the overall value of a work is through its serving as a vehicle for some further positive cognitive value. It seems that not all cases of the paradox fit within this pattern and that a non-instrumental role could be, in principle, identified in order to solve the puzzle.

A fourth solution has been offered which also tries to diminish the air of paradox by weakening the idea that aesthetic value should be basically understood in terms of pleasure. Hence, this solution elaborates on a notion of aesthetic value, which is not exhausted by the notion of aesthetic pleasure but may include other aspects such as a work's being attention-calling, absorbing, appealing, or mesmerizing. ${ }^{16}$ Thus, in thinking about the value that some experiences of disgust in art may possess, C. Korsmeyer (2011) has defended the idea that we should embrace a broader view of aesthetic value; one which may both include pleasure as well as other valuable but not necessarily pleasurable feelings, such as disgust. Here the strategy is not so much to diminish the negative affective quality of the experience triggered by the work but to redefine aesthetic value in such a way that its nature does not conflict with those works which typically elicit unpleasant feelings. According to this last proposal, the paradox precisely arises because we have implicitly endorsed a hedonic view of aesthetic value. However, following Ridley (2003), if we reject the hedonic view, there is no puzzle to solve when confronting works whose very artistic value seems to be grounded on the negative feelings they elicit. In a nonhedonic view of value, painful artworks or works that typically cause negative feelings need not pose any puzzle to the question of aesthetic value. If we embrace a broad view of aesthetic value and if we get rid of the idea that pleasure must be an essential ingredient of aesthetic value, these works would no longer pose any puzzle.

Although it may be true that the notion of aesthetic value has sometimes been conceived under a narrow hedonic light, I think we should at least attempt to preserve a notion of aesthetic value, 
which does not completely divorce itself from some notion of a pleasurable experience or response. The reason why I think some form of pleasure must be at the core of our notion of aesthetic value is that it seems that, even in the paradoxical examples, or maybe particularly in these cases, the problem we seem to be dealing with necessarily involves some appeal to pleasure. By getting rid of pleasure as a key feature of aesthetic value, we get rid of the paradox as well, but I think that we do so at the price of distorting what puzzled us in the first place.

Before concluding this section in which I have tried to review some of the alternative proposals that have been offered to solve the paradox, I would like to mention one view of aesthetic value, which contains some of the ingredients that I think we should preserve, although, as I will try to show, my proposal also departs from this. This view, which can be derived from Adorno's thought on aesthetics, ${ }^{17}$ could be located in between the third and fourth alternatives spelled out above, but I think it also distinguishes itself from them in crucial respects. For this reason, I think it deserves to be mentioned on its own.

In his complex view of aesthetic value in Aesthetic Theory, Adorno establishes a strong connection between artistic value and aesthetic discomfort in modern art. The negative character of aesthetic value is, in turn, grounded on the historical development of both art and society. That is, the need to reclaim a disturbing aesthetic quality as the grounding value of art derives from the acknowledgment that the realm of society, or history, has proved to be the source of massive pain. The history of the twentieth century is, in Adorno's diagnosis, a history of massacres and corpses, a history, therefore, where there is no legitimate place for beauty or pleasure. It is then by its relationship to society that art's nature becomes entangled with aesthetic displeasure or disturbance. Contemporary art can truly reflect the painful condition of modern society only by eliciting disturbing experiences or by frustrating our aesthetic expectations. In this sense, aesthetic value becomes necessarily identified with a negative experience, one in which the viewer experiences the failure to grasp or understand, to make aesthetic sense of, the work's meaning. This aesthetic dissatisfaction becomes, then, the true mark of genuine art, for it reminds us of the real suffering that overshadows contemporary society.

Thus, in Adorno's view, not only does negative experience become the key notion for aesthetic value, pleasure itself becomes alien or even contrary to aesthetic value. Works of art that succeed in producing a pleasurable experience in the viewer are deceitful and 
both artistically and aesthetically bad following this diagnosis. Adorno's rejection of a characterization of aesthetic value in terms of pleasure is intimately linked to his dialectical view on the relationship between art and reality. Only artworks that elicit struggle and distress, and which make their full apprehension difficult for the spectator, can escape the trivializing and deceitful effects of beauty. ${ }^{18}$ A key aspect of Adorno's view - even if his view is not directly concerned with the alleged paradox we are dealing with in this article - is that he locates displeasure - or at least, confusion and bewilderment - at the core of aesthetic value. In his view this is not only non-paradoxical but also historically required. ${ }^{19}$ Moreover, his notion of aesthetic value is not just the reverse of beauty but it contains the elements that explain why there is value in painful art: By frustrating the viewer's expectations and by precluding her attempts to make (aesthetic) sense of what she contemplates, the work elicits reflection and makes the viewer become aware of the impossibility of reconciliation. The more successful the work is in provoking a disturbing experience the higher its artistic value and artistic truth. The rejection of pleasure at the core of aesthetic value should not be merely understood as the defence of a new aesthetics of the ugly or the disgusting. Adorno is not concerned with aesthetic properties as such. Rather, his interest focuses upon the value of a kind of aesthetic experience whose articulation precludes an easy understanding and, hence, pleasure. Artistic value becomes characterized precisely in terms of a work's achievement in leaving the spectator perplexed. ${ }^{20}$

Although Adorno's view can be considered as a robust attempt to define aesthetic value in negative terms or in terms that give a central role to negative experiences, I think we should not completely give up on the idea that aesthetic value is connected to some form of aesthetic pleasure, or with the possibility of making aesthetic sense of even what may be characterized as disconcerting or disturbing. In this sense, although I think Adorno's view of negative aesthetics can provide some insight into the value attached to negative experiences in art, I think we can still preserve, if minimally, a notion of aesthetic value that is connected to aesthetic pleasure - even when this pleasure might need to be understood in complex ways. In order to support this idea I will in the following section turn to some features of aesthetic experience as described by Kant, which I think may help us to see why there is no need to give up completely on the idea that aesthetic experience is linked to pleasure in order to account for the place that negative experiences may have in the constitution of aesthetic value. 
I think we can aim at clarifying the puzzle of negative emotions and aesthetic value by looking at Kant's view of aesthetic reflection and aesthetic judgment. ${ }^{21}$ In this sense, I think part of the solution to the paradox can derive from a proper understanding of aesthetic value as grounded on aesthetic reflection; that is, I hope to argue for an understanding of aesthetic value that is able to accommodate the fact that a work may possess great aesthetic value while triggering negative emotions in the spectator. In this sense, I think that a proper way of addressing this problem lies not so much in discovering how it is possible that we experience pleasure when enduring negative emotions, 22 but in showing that a view of aesthetic value as fundamentally grounded upon pleasure is not at odds with cases where negative emotions are involved. It is in relation to this problem I think Kant's view of reflective judgment can be fruitfully invoked. 23

Although there is much debate about how to properly interpret Kant's view on aesthetic judgment and reflection, ${ }^{24}$ I will focus upon some aspects that may be considered uncontroversial. My aim is to show that if we focus upon these features of Kant's view on aesthetic judgment as the judgment through which aesthetic value is expressed or communicated, we may have a possible solution to the apparent puzzle of the negative emotions and aesthetic value.

Aesthetic reflection, in Kant's view, is first of all a form of aconceptual judgmental activity. This means that aesthetic experience according to Kant is not characterized as the passive reception of a particular perceptual content but as a form of experience where our judgmental abilities are in play. Nevertheless, although aesthetic experience is one of the forms in which we exercise our faculty of judgment - the faculty of judgment being the faculty through which we place or synthesize some perceptual manifold under a universal - the use of this faculty in aesthetic contexts is carried on in an a-conceptual manner. This, in Kant's terminology, means that the resulting synthesis from the operations that our judgmental capacities produce does not correspond to any concept or rule. That is, our faculties synthesize the perceptual manifold without referring that synthesis to any concept or universal.

Nevertheless, Kant thinks that aesthetic judgments exhibit what he calls "merely formal purposiveness" or "the form of purpose”. If perceiving an object under a concept is to perceive its form as related to a particular purpose, in aesthetic experience we experience the form of the object "as if" it were governed by some 
purpose but without referring that form to any particular purpose or concept. This is also the reason why in the aesthetic judgment the free play of the Imagination and the Understanding is involved. Given that no concept or rule is involved, the Imagination freely produces a synthesis which does not correspond to any concept but that is still experienced with pleasure. In this sense, the idea of a merely formal purposiveness as the perceptual content of aesthetic judgment allows Kant to introduce some sense of finality, or normativity, which asserts itself in spite of the lack of concepts or rules. In Kant's own words: "the mere form of purposiveness in the representation through which an object is given to us, insofar as we are conscious of it, can constitute the satisfaction that we judge, without a concept, to be universally communicable, and hence determining ground of the judgment of taste.” (§ 11, p. 106). Aesthetic judgments are thus judgments that establish the normative character of a particular formal synthesis - which has been achieved through the free play of the Understanding and the Imagination - through the disinterested pleasure ${ }^{25}$ that results from experiencing the normative character of that synthesis. Even though the judgment of beauty is based upon the subjective feeling of pleasure it makes a claim to universality - that is, to its validity for everyone - precisely in virtue of its disinterested character.

Although this is an extremely brief summary of Kant's view, I think that some of the key features of his view on aesthetic judgment can be helpful in order to delineate a possible solution to our initial puzzle. First, we have seen that if the aesthetic judgment or the judgment of taste is one through which we establish that a particular object necessarily elicits aesthetic pleasure, it seems that we cannot coherently attribute aesthetic worth to an object or artwork while denying the experience through which we experience the object as aesthetically worthy or one of pleasure. It seems conceptually impossible to ascribe aesthetic value or to endorse an aesthetic judgment, in Kant's sense, without experiencing the sort of disinterested pleasure that Kant has introduced as the mark of aesthetic value. In this sense, at least within a Kantian framework we cannot account for aesthetic value without accepting the fundamental role of pleasure. If this sort of pleasure does not accompany the affective response towards a particular a-conceptual synthesis, we cannot feel legitimated to proclaim its aesthetic worth or beauty.

However, as I will try to argue, endorsing this view and the emphasis on pleasure it carries with it, does not preclude that some negative qualities are experienced as part of the synthetic whole that 
grounds aesthetic pleasure; a work may be made out of a plurality of elements or features (both positive and negative). Individually taken, some of these features may be of a negative quality in the sense that they can provoke typical negative responses. However, the negative character of some of the particulars involved in the synthetic whole do not necessarily prevent that whole from being experienced as pleasurable. In fact, the negative aspect may play an important role in the configuration or synthesis that we experience with pleasure, so that if we deprive the object of it, the whole experience would be transformed for the worse.

To illustrate this with a simple example: a pattern of sound that may be experienced negatively can be precisely what makes sense within a particular musical work, thus making the overall experience aesthetically valuable. A musical example to illustrate this could be certain out-of-tune fragments that we can listen to in Shostakovitch's Symphony No. 10. Although when taken in isolation these fragments seem to cause displeasure, their relationship to the rest of the symphony allows them to be experienced as fitting or adequate, and hence as contributing to the overall pleasure the symphony seems to elicit and which leads to our aesthetic praise.

Similarly, narrative artworks may exploit the force of some negative qualities while making the overall narrative experience pleasurable or worth experiencing. In this sense, it seems that the presence of negative qualities in an artwork or object does not necessarily prevent the object as a "mere purposiveness," in Kant's terms, being experienced with pleasure. Aesthetic value as grounded on an experience of pleasure is thus compatible with the work's ability to elicit some negative affective response as part of the overall aesthetic experience.

A different angle, which can help us to see to what extent this understanding of aesthetic experience can help us solve the problem of negative emotions and aesthetic value, is to examine whether it fits in with some clear examples that have been partly inspiring those who have accepted the puzzle in the first place. If we look at examples of contemporary art it seems that the traffic with negative emotions, affective responses, or qualities has become a usual suspect. Although this tendency has sometimes been interpreted as a rejection of aesthetic value as an essential feature of art, I think this is not the only available explanation for these provocative works. In fact, some works which intentionally and assertively exhibit negative properties do so in a way that results in what can be described as aesthetic success, thus provoking a more disturbing overall experience. Works such as Piss Christ (Andrés Serrano, 
1987) or photographs by Mapplethorpe or Cindy Sherman can be good examples of how the display of negative qualities and the corresponding negative affective response they trigger may be an essential part of the overall aesthetic worth we find in these works. The disturbing effect of, for example, C. Sherman's self-portraits in the series Untitled Film Stills (1978) is part of the reason why we attach great aesthetic success to them. They are aesthetically good precisely because of the anxious feeling they seem to elicit and without which the work would be aesthetically poorer.

Although some would be reluctant to talk about pleasure simpliciter in these cases and have tried to find other terms of praise which avoid the terminology related to the notion of pleasure, I think these works deserve our praise precisely because they are able to make us experience their elements as fitting or coherent (or as making sense). This experience, which relates to the form of the object - the disposition and the relationship of its elements - to a feeling of pleasure is what, following Kant, constitutes the basis of aesthetic judgment.

These cases seem to confirm that negative emotions or experiences might be crucial aspects of art's appreciation while preserving the idea that aesthetic value is still a matter of experiencing a particular, disinterested, sort of pleasure. A pleasure that cannot be understood merely as a function of the emotions or experiences the artwork elicits in the spectator, but as one whose canonical basis concerns the way in which the constitutive elements of the work are put together. Goya's pathetic outlook or Sherman's disgusting images are not simply pathetic or disgusting. They gather these qualities within a broader artistic project whose presentation deserves the viewer's applause. This, I think, is the best explanation for the alleged paradox that art that typically elicits negative experiences presents for a pleasure-based view of aesthetic value. We do not need to get rid of the negative experience or transform it into something positive. Rather we need to acknowledge the role it can play within a broader aesthetic complex: a role that could not be simply performed by a different sort of emotion or experience and, perhaps, without which aesthetic pleasure could not have arisen.

Another way of showing how the positive or negative valence of some qualities does not necessarily solely determine a work's aesthetic value - for this only depends upon the formal relation of those qualities - is to look at examples which we will describe as aesthetic failures in spite of the fact that their constitutive elements may all be of a positive character. Kitsch works can illustrate this, for example. Kitsch artworks or objects are usually "pretty" 
in the sense that they usually feed on positive qualities such as terse surfaces, mild, pastel, colours, or soft shapes. However, we condemn them aesthetically because the experience they offer is poor and therefore aesthetically unsuccessful. In Kantian terms, kitsch will fail to elicit a proper aesthetic judgment or an aesthetic experience because it would not give rise to the free play of the Imagination and the Understanding in a rich way. As the case of kitsch art confirms, aesthetic value neither depends, nor derives from the particular valence of the particular features involved in the constitution of an aesthetic whole. Rather, it is grounded on the feeling of pleasure, which derives from experiencing that a particular aesthetic whole is consistent or possesses the mere form of purpose that stimulates the free play of the Understanding and the Imagination.

Before summarizing the proposed solution to the problem or puzzle of the negative emotions and aesthetic value, I would like to introduce a couple of remarks that may be pointed out which are against this proposal.

First, it could be said that nothing of the view proposed could help us to understand why it is the case that we sometimes experience pleasure in experiencing painful emotions through art. And that, to that extent, I have failed to address the puzzle of negative emotions in the sense that I have offered no explanation of the phenomenon that seems to trigger the puzzle in the first place. Although I think this is true of my proposal, I think my aim has not been so much to address the problem of how pleasure can derive from negative emotions but how aesthetic pleasure can obtain in spite of the presence of negative emotions involved in the work's characteristic experience. In this sense, I have left unresolved the question of how certain negative emotions can also be experienced as pleasurable (maybe in art as well as in life). As I pointed out at the beginning, I have concentrated on the conflict there seems to be between a view of aesthetic value based on pleasure and our finding value in works that typically arouse problematic emotions - and whose aesthetic value seems therefore problematized if we try to deal with it in terms of pleasure. My aim has been to show that there is no need to give up on the idea that aesthetic pleasure is at the core of aesthetic value when we face cases where the paradox of negative emotions seems to be exemplified.

Secondly, it may seem that given the framework proposed, nothing could, in principle, prevent some strongly negative features from being constitutive of aesthetic value or that, as it has been often put, "everything could be experienced aesthetically.” That 
is, it seems to follow from this proposal that in spite of the strong negative character of the qualities embodied in an artwork, it might be possible to experience the work as aesthetically valuable. Are there limits to what can be experienced aesthetically? Or, to quote Carole Talon-Hugon's 26 title L'art, peutil tout montrer?

My view here is that a sensible answer to this question cannot be provided in the absence of empirical evidence. I think that the answer that would follow from Kant's view on aesthetic judgment is that there are no a priori limits for the sort of properties that can enter into the free play of the faculties that constitutes aesthetic pleasure. ${ }^{27}$ However, it may be a matter of how precisely certain properties enter into an aesthetic relation that determines whether they can or cannot be experienced from an aesthetic point of view. And this, given the necessarily particular character of the aesthetic synthesis, is something that can hardly be established a priori. In this sense, I think it is possible that some properties, especially when they are experienced in a literal way, frustrate our attempt to aesthetically make sense of a particular work. But my impression here is that the resistance to aesthetic sense or the aesthetic frustration experienced towards these works is more related to the literalness through which some of their properties are given to us. ${ }^{28}$ In this sense, while I do not believe everything can be experienced aesthetically or as provoking a significant aesthetic experience, I do not think it is impossible that some clearly negative qualities can greatly contribute to aesthetic value.

\section{CONCLUSION}

In this article I have tried to defend the view that a notion of aesthetic value based on pleasure can stand even when distinctive examples of good art involve experiencing negative feelings. In this sense, I have not addressed the issue of how it is possible to experience pleasure out of enduring difficult emotions (which I think may be a matter which requires psychological explanation). Rather, I have concentrated upon how a notion of aesthetic value that is intimately connected to a pleasurable response can deal with cases in which the work's typical emotional response seems to be negative or involve negative feelings. Given this delimitation of the problem, I have tried to show why some of the solutions to the puzzle seem inadequate. While some tend to attenuate the negative aspect involved in order to explain the resulting pleasurable experience, others put the emphasis on the negative emotional response at the cost of giving up a pleasure-based notion of aesthetic value. My aim has been to show we can do justice to both aspects without 
giving up on the idea that aesthetic value is necessarily linked to an experience of pleasure.

In order to defend this approach I have made use of Kant's view on aesthetic reflection and aesthetic judgment. I think his emphasis on the ideas of disinterested pleasure at the representation of a mere formal purposiveness through the free play of the Imagination and the Understanding provides the very elements we need in order to grant a place for different sorts of qualities, both positive and negative, while preserving the core idea that aesthetic value is based upon pleasure.

An aesthetic experience can be considered to be valuable if pleasure results from experiencing the synthetic process - which is carried out freely, without any conceptual restraint - of aesthetic reflection. Thus, the felt pleasure is evidence of the consistency with which a particular formal arrangement is experienced. What matters is that the synthesis resulting from the free play of the faculties - or, aesthetic reflection - is experienced as pleasurable or with pleasure.

This suggests that the qualities or properties that may be experienced may possess different valences and need not be positive themselves. What matters is not whether a work possesses more or less negative qualities, but the way in which these qualities are presented to us, and are grasped in aesthetic reflection. A work may be pleasurably sombre if its sombreness contributes to an aesthetic synthesis (that is, an a-conceptual but articulated whole), which is experienced with pleasure. In a sense, the negative or positive valence of particular properties of a work may be irrelevant for determining whether the work is aesthetically valuable - i.e., pleasurable. Notice that aesthetic pleasure is not even granted by the presence of exclusively positive properties. If we look, for example, at works which are condemned, such as kitsch, it is easy to see that the sum of pleasing qualities do not amount to aesthetic value. For kitsch - if it is experienced as kitsch - does not issue in aesthetic pleasure, but in aesthetic discontent.

Thus, if the aesthetic synthesis resulting from the free play of the faculties is experienced with pleasure, the aesthetic judgment will be positive, however other negative qualities may be involved. If these negative qualities are constituents of an overall pleasurable synthesis, they do not need to challenge the idea that aesthetic value is grounded in pleasure. This does not involve rejecting the negative quality of those properties or the negative emotions that may be elicited by them. In fact, it may be the case that a particular aesthetic synthesis is pleasurable in the way it is precisely because 
of the role played by the negative response elicited by certain qualities. In this sense, the solution offered here does not need to give up on the idea that the negative qualities remain negative throughout. If they contribute to a broader pleasurable experience their negativity does not have to be necessarily conceived as the source of a puzzle. ${ }^{29}$

\section{NOTES}

1. Although the paradox was firstly conceived in terms of the pleasure typically afforded by tragedy, the philosophical literature has expanded the range of the problem to other genres that typically arouse negative emotions or feelings and to other works that intentionally aim at provoking negative affective responses in the spectator.

2. David Hume, "Of Tragedy" [1777] in Essays. Moral, Political and Literary, ed. Eugene F. Miller (Indianapolis: Liberty Fund, 1987), 216-225.

3. A recent compilation that extensively addresses this issue is Suffering Art Gladly. The Paradox of Negative Emotion in Art, ed. Jerrold Levinson (New York: Palgrave Macmillan, 2014). Other recent contributions are Katerina Bantinaki, "The Paradox of Horror: Fear as a Positive Emotion," Journal of Aesthetics and Art Criticism 70 (2012): 383-392; Jeanette Bicknell, Why Music Moves Us (New York: Palgrave Macmillan, 2009); Noël Carroll, The Philosophy of Horror, or Paradoxes of the Heart (Routledge, 1990); Gregory Currie, "Tragedy," Analysis 70 (2001): 632-638; Susan Feagin, "Monsters, Disgust, and Fascination," Philosophical Studies 65 (1992): 75-84; Susan Feagin, “The Pleasures of Tragedy," American Philosophical Quarterly 20 (1983): 95-104; Carolyn Korsmeyer, Savouring Disgust: The Foul and the Fair in Aesthetics (Oxford: Oxford University Press, 2011); Jerrold Levinson, "Horrible Fictions," Journal of Aesthetics and Art Criticism 49 (1991): 253-258; Aaron Neill, "On a Paradox of the Heart," Philosophical Studies, 65 (1992): 53-65; Aaron Neill, "'An Unaccountable Pleasure': Hume on Tragedy and the Passions," Hume Studies 24 (1998), 335-354; Aaron Ridley, "Tragedy" in Oxford Handbook of Aesthetics, ed. Jerrold Levinson (Oxford: Oxford University Press, 2003), 408-420; Aaron Smuts, "The Paradox of Painful Art," Journal of Aesthetic Education 41 (2007): 59-76; Carole TalonHugon, Goût et dégoût : l'art peut-il tout montrer? (J. Chambon, coll. Rayon art: Nîmes, 2003).

4. Hume's account in his "Of Tragedy" is usually understood along these lines.

5. Cognitive accounts of the value of tragic emotions, such as Feagin's (1983) usually take this line of thought.

6. Prominent defenders of this approach are Smuts (2007) and Ridley (2003).
7. Notice that the puzzle, at least in the form I am presenting it here, is not about how it is possible that we find pleasure in experiencing negative emotions tout court. Although this problem could also be explored, my impression is that the answer to this problem lies within the realm of psychological explanation. This is, for example, one of the questions that Carolyn Korsmeyer presents in her book on disgust (see Korsmeyer 2011). The problem I will be concerned with is not so much about how it is possible that some negative feelings can also cause us pleasure but how the negative affective character can be made compatible with a notion of aesthetic value that is grounded on pleasure.

8. "This extraordinary effect proceeds from that very eloquence, with which the melancholy scene is represented. The genius required to paint objects in a lively manner, the art employed in collecting all the pathetic circumstances, the judgment displayed in disposing them: the exercise, I say, of these noble talents, together with the force of expression, and beauty of oratorical numbers, diffuse the highest satisfaction on the audience, and excite the most delightful movements. By these means, the uneasiness of the melancholy passions is not only overpowered and effaced by something stronger of an opposite kind; but the whole impulse of those passions is converted into pleasure, and swells the delight which the eloquence raises in us." (Hume, 219-220).

9. "It seems an accountable pleasure, which the spectators of a well-written tragedy receive from sorrow, terror, anxiety, and other passions, that are in themselves disagreeable and uneasy. The more they are touched and affected, the more are they delighted with the spectacle; and as soon as the uneasy passions cease to operate, the piece is at an end." (Hume, 216).

10. Although the issue of the possibility of music's arousal of the garden-variety emotions is not uncontroversial and some prominent authors, such as Peter Kivy (1989 and 2001), have denied that music can elicit ordinary emotions in the listeners, I think that we should aspire to offer a solution to the puzzle of negative emotions in art which could, in principle, account for different sorts of cases - including those that contemplate the possibility that non-representational works of art could possess this affective component. See Peter Kivy, Sound Sentiment (Philadelphia: Temple University Press, 1989) and Peter Kivy, New Essays on Musical Understanding (Oxford: Clarendon Press, 2001). 
11. See, for example, Kendal Walton, "Spelunking, Simulation, and Slime: On Being Moved by Fiction" in Emotion and the Arts, ed. M. Hjort and S. Laver (New York: Oxford University Press, 1997), 37-49.

12. Cain Todd, "Attention, Negative Valence, and Tragic Emotions" in Suffering Art Gladly. The Paradox of Negative Emotion in Art, ed. Jerrold Levinson (New York: Palgrave Macmillan, 2014), 224-245. Jonathan Gilmore has also offered his own analysis of the paradox and he also thinks that emotions felt towards fictional events are not exactly like ordinary emotions although they may resemble them in some respects; see Jonathan Gilmore, "That Obscure Object of Desire: Pleasure in Painful Art" in Jerrold Levinson op.cit., 153-170.

13. Some prominent defenders of this view can be Martha Nussbaum, Upheavals of Thought: The Intelligence of Emotions (Cambridge: Cambridge University Press, 2001); Susan Feagin, "The Pleasures of Tragedy," American Philosophical Quarterly 20, (1983): 95-104, or Flynt Schier, "The Claims of Tragedy: An Essay in Moral Psychology and Aesthetic Theory," Philosophical Papers 18 (1) (1989): 7-26.

14. Again, if we think of negative emotions triggered by music it is not obvious that some cognitive value is obtained through this sort of experience.

15. Thus, although in watching Othello we may explore in a deep manner the devastating effects of irrational jealousy, one does not need to see the play in order to become aware of these effects or in order to have learnt about them.

16. Some approaches that seem to solve the puzzle by expanding the notion of aesthetic beyond the idea of pleasure are Ridley's (2003), Korsmeyer's (2011), and Smuts' (2014).

17. Theodor W. Adorno, Aesthetic Theory [1970], translated by Robert Hullot-Kentor (London, New York: Continuum, 2002).

18. Adorno's rejection of beauty and its consolatory effects was not only defended from a purely philosophical or theoretical perspective. What Danto refers to as the "intractable avant-garde" shared a similar attitude towards beauty or any other kind of positive experience that art could afford. (see Arthur Danto, The Abuse of Beauty. Aesthetics and the Concept of Art (Open Court: Chicago and La Salle, Illinois, 2003).

19. If beauty has been a symbol of reconciliation, there cannot be any room for it after the historical failure of Enlightenment's project.

20. Adorno's view could be considered as an attempt to characterize the notion of aesthetic value in terms that are not limited by an experience of pleasure. His reasons, however, appeal to a historical necessity which is usually absent in other accounts which also favour a broad notion of aesthetic value.

21. Immanuel Kant, Critique of Judgment [1790], translated by Paul Guyer (Cambridge: Cambridge University Press, 2000).
22. As I have pointed out above this would be a problem for psychologists to solve. In fact, I think what is usually known as the paradox of painful art cannot be merely answered by focusing upon the alleged psychological mechanisms that explain our eventual enjoyment of negative experiences. This sort of enquiry, although clearly valuable, cannot provide a full explanation of the paradox as it arises in the experience of artworks. Our puzzlement is not merely how it is possible that we obtain some positive experience or feeling from overall negative experiences, but how it is possible to defend a view of aesthetic value in terms of pleasure while acknowledging that some great artworks afford negative experiences; that is, displeasure.

23. I owe the need to refine this point to the comments of an anonymous referee.

24. Some of the more prominent studies of Kant's aesthetics are Kant's Critique of the Power of Judgment: Critical Essays, ed. Paul Guyer (Lanham, Maryland: Rowman and Littlefield, 2003); Hanna Ginsborg, The Normativity of Nature. Essays on Kant's Critique of Judgement (Oxford: Oxford University Press, 2015); Henry E. Allison, Kant's Theory of Taste (Cambridge: Cambridge University Press, 2001); Donald W. Crawford, Kant's Aesthetic Theory (Madison, Wisconsin: University of Wisconsin Press, 1974); Robert B. Pippin, "The Significance of Taste: Kant, Aesthetic and Reflective Judgment," Journal of the History of Philosophy 34 (4) (1996): 549-69; Eva Schaper, Studies in Kant's Aesthetics (Edinburgh: Edinburgh University Press, 1969).

25. In Kant's view, disinterested pleasure means that it is experienced or obtained independently from any concern or desire towards the object's existence.

26. Carole Talon-Hugon, Goût et dégoût: l'art peut-il tout montrer? (J. Chambon, coll. Rayon art: Nîmes, 2003).

27. Kant notably made one exception with the disgust.

28. Although I cannot expand on the idea of literalness here, I think that the aesthetic failure that some contemporary works can exemplify is not so much due to their use of negative qualities as such but with the literal use of them. In fact, I think that some of the responses towards these works are aesthetically unsatisfactory, not because of the negative qualities they exhibit but because they exhibit them literally. In this sense, works, which do not necessarily traffic with negative qualities, may also fail aesthetically because of their literal quality. For a proper characterization of the notion of literalness see Michael Fried, Art and Objecthood: Essays and Reviews (Chicago and London: University of Chicago Press, 1998).

29. This work has been made possible thanks to the financial support from the Program ‘Jóvenes Líderes en Investigación de la Fundación Séneca-Agencia de Ciencia y Tecnología de la Región de Murcia' (18958/JLI/13) "El valor estético y su interacción con otros valores en la práctica apreciativa" and (FFI2015-64271-P) "Experiencia estética de las artes y complejidad de la percepción" (Ministerio de Economía y competitividad) 2016-2020. 